\title{
Commuters' attitudes and norms related to travel time and punctuality: A psychographic segmentation to reduce congestion
}

\author{
Haustein, Sonja; Thorhauge, Mikkel; Cherchi, Elisabetta
}

Published in:

Travel Behaviour and Society

Link to article, DOI:

10.1016/j.tbs.2018.04.001

Publication date:

2018

Document Version

Peer reviewed version

Link back to DTU Orbit

Citation (APA):

Haustein, S., Thorhauge, M., \& Cherchi, E. (2018). Commuters' attitudes and norms related to travel time and punctuality: A psychographic segmentation to reduce congestion. Travel Behaviour and Society, 12, 41-50. https://doi.org/10.1016/j.tbs.2018.04.001

\section{General rights}

Copyright and moral rights for the publications made accessible in the public portal are retained by the authors and/or other copyright owners and it is a condition of accessing publications that users recognise and abide by the legal requirements associated with these rights.

- Users may download and print one copy of any publication from the public portal for the purpose of private study or research.

- You may not further distribute the material or use it for any profit-making activity or commercial gain

- You may freely distribute the URL identifying the publication in the public portal 


\title{
Commuters' attitudes and norms related to travel time and punctuality: A psychographic segmentation to reduce congestion
}

\author{
Sonja Haustein * \\ Department of Management Engineering, Technical University of Denmark, \\ Diplomvej 372, 2800 Kgs. Lyngby, Denmark, sonh@dtu.dk

\section{Mikkel Thorhauge} \\ Department of Management Engineering, Technical University of Denmark, \\ Bygningstorvet 116B, 2800 Kgs. Lyngby, Denmark, mtho@dtu.dk

\section{Elisabetta Cherchi} \\ School of Civil Engineering and Geoscience, Newcastle University, \\ Cassie Building, NE1 7RU, UK, Elisabetta.Cherchi@newcastle.ac.uk \\ * Corresponding author
}

\begin{abstract}
Congestion remains one of the most prevalent transport problems in big cities. As a starting point for more targeted interventions to reduce congestion, this paper suggests a segmentation of commuters. Based on psychographic factors derived from an expanded Theory of Planned Behaviour, we identify three distinct commuter segments: (1) Unhurried timely commuters, who find it very important to arrive on time but less important to have a short travel time; (2) Self-determined commuters, who find it less important to arrive on lime and depend less on others for their transport choices; and (3) Busy commuters, who find it both important to arrive on time and to have a short travel time. Comparing the segments based on background variables shows that Self-determined commuters are younger and work more often on flextime, while Unhurried timely commuters have longer distances to work and commute more often by public transport. Results of a discrete departure time choice model, estimated based on data from a stated preference experiment, confirm the criterion validity of the segmentation. A scenario simulating a toll ring illustrates that mainly Self-determined commuters would change their departure time as a response to this economic intervention, while we suggest alternative interventions for the two other segments. The results stress the need for more targeted efforts to change departure time choice and point to ways to improve the suggested segmentation approach.
\end{abstract}




\section{Introduction}

Congestion remains one of the most prevalent transport problems in big cities around the world. Rush-hour commuting increases fuel consumption and emissions and thereby the negative impact of motorised transport on public health and the environment (e.g., De Vlieger et al., 2000; Levy et al., 2010). Moreover, time and fuel wasted in traffic congestion comes with considerable - though hard to estimate - economic costs (e.g., Lo et al., 2016; Morris \& Hirsch, 2016).

Congestion can be tackled by two changes in commuters' travel behaviour: modal shifts and departure time shifts. Measures to achieve such behavioural changes are divided into two groups: structural (or 'hard') measures and cogitive-motivational (or 'soft') measures (Vlek, 2004). The most common hard measures to reduce congestion are pricing policies that increase costs for travelling during rush hours (e.g., road pricing in city centres, public transport ticket pricing). Opposed to hard measures, which focus on infrastructure and regulations, soft measures aim for voluntary changes of travel behaviour, achieved for instance by information provision, awareness raising or social modelling. To develop targeted (and thus more efficient) soft measures, knowledge about the motivations and needs of potential target groups is crucial. Therefore, the development of soft measures is advantageously proceeded by a market segmentation (e.g., Anable, 2005; Beirão and Sarsfield Cabral, 2007; McKenzie-Mohr, 2000). So far, segmentation studies and related targeted measures have mainly been developed as a basis for modal shifts but not for departure time shifts.

This paper suggests psychographic commuter segmentation as a basis for targeted measures to change departure time. We focus on departure time choice because individuals are more likely to change departure time as a response to congestion than to change their preferred travel mode (Bianchi et al., 1998; Hendrickson and Planke, 1984; Hess et al., 2007a; Kroes et al., 1996). We use a psychographic segmentation because commuters differ in the motivational basis for departure time choice (e.g., Fujii and Kitamura, 2004), which should be taken into account when trying to shift demand away from rush hours.

The remainder of this paper is organised as follows: Section 2 provides the background of this paper both on modelling departure time choice (Section 2.1) and applying segmentation studies in transport research and practise (Section 2.2). Section 3 describes the data basis and applied methods of data analysis. Section 4 presents the results in three subsections: Section 4.1 describes the identified commuter segments; Section 4.2 assesses the congruent validity of the segments based on a discrete choice model; and Sections 4.3 demonstrates to what extent the different commuter segments reschedule their departure time choice in a tollring scenario. In Section 5 we discuss possible interventions, the limitations of the suggested segmentation and how these can be addressed in future studies. Section 6 discusses broader theoretical and practical implications of the results. 


\section{Background}

\subsection{Departure time choice}

Within the transport literature, the predominant way of modelling departure time choice is the Scheduling model (SM; Small, 1982), which assumes that individuals select their departure time as a trade-off between travel time and scheduling delay. The scheduling delay is a re-scheduling penalty that measures differences in the actual arrival time and the preferred arrival time. Previous studies have also extended the scheduling model by considering travel cost (Small, 1987), a discrete lateness penalty (Noland and Small, 1995), and travel time variability to measure reliability (Noland and Small, 1995; Small et al., 1995).

In addition, flexibility is crucial when studying departure times. Most studies only focus on the temporal flexibility of the commuting trip from home to work (e.g., Arellana et al., 2012; Börjesson, 2007; Börjesson et al., 2012; De Jong et al., 2003; Kristoffersson, 2013; Polak and Jones, 1994; Small, 1982), while Thorhauge et al. (2016a) considered the full daily activity pattern and whether these activities were fixed or flexible. They found that other activities performed on the way to or from work or in the evening impact individuals' departure time in the morning (i.e. segments with other non-work activities in the morning, afternoon or evening are less likely to reschedule).

Apart from objective aspects, such as travel time and costs, as well as framework conditions, such as fixed working hours and activity patterns, also subjective aspects, such as subjective norm, the perception of control, and attitudes are relevant for departure time choice as Thorhauge et al. (2016) demonstrated when integrating the Theory of Planned Behaviour (TPB, Ajzen, 1991) in a discrete choice model to explain departure time choice. The relevance of subjective norm (SN) to arrive on time has also been shown by Fujii and Kitamura (2004). Both studies indicate that people who feel pressure by relevant others to arrive on time are less likely to reschedule their departure time when this may cause delays than people with lower SN. In contrast to SN, personal norm (PN) measures the intrinsic feeling of moral obligation to behave in accordance with the individual value system (Schwartz, 1977). In the context of departure time choice PN refers to the perceived intrinsic obligation to arrive on time. While PN has often been integrated in models to explain mode choice (e.g., Bamberg et al., 2007; Lo et al., 2016), the effect of PN on departure time choice has not been studied yet.

With regard to attitudes, Thorhauge et al. (2016) have shown that people, who find it important to arrive on time, are less likely to reschedule, while people who find it important to have a short travel time, are more likely to reschedule their departure time in order to reduce travel time. Why people find it more or less important to minimise their travel time may be related to the actual living situation and complexity of daily routines. Haustein and Hunecke (2007) introduced the concept of perceived mobility necessities (PMN) to account for such effects of the actual living situation (e.g., complex daily routines due to children and 
employment) in transport related decisions. According to Thorhauge et al. (2016) people with high PMN are less likely to reschedule their departure time than people with low PMN.

\subsection{Segmentation in the transport sector}

In market segmentation, the population is divided into homogeneous sub-groups with similar attributes (e.g., age, attitudes, values, place of residence) that are considered as or related to the motivational basis of the targeted behaviour. This approach is motivated by the aim to create more targeted and thus more efficient interventions (e.g., McKenzie-Mohr, 2000). In addition, the characterisation of population segments is easier to communicate to practitioners as compared to abstract statistical models and thus more likely to be taken up for the design of concrete interventions in the transport sector (e.g., Schubert and Kamphausen, 2006).

Segmentation approaches in the transport sector can be divided by the factors that are used as a basis for segmentation: spatial factors (e.g., Hunecke et al., 2010), socio-economic factors (e.g., Hildebrand, 2003; Ryley, 2006), psychographic factors (e.g., Anable, 2005; Pronello and Camusso, 2011), the travel behaviour itself (e.g., Böhler et al., 2006; Prillwitz and Barr, 2011) or a combination of different kind of factors. The suitability of the different approaches depends on the area of application (Haustein and Hunecke, 2013).

With regard to departure time choice, demographic factors, such as age, education, household type, and employment (white collar workers, part time workers, frequent home-worker, flexible work hours) have been found to be relevant factors (Small, 1982) as well as trip characteristics. In addition, Oakail et al. (2016) demonstrated that gender and childcare responsibilities are important factors of rush-hour commuting. A few studies used these factors as a basis for segmentation. De Jong et al. (2003) and Hess et al. (2007b) divided travellers into sub-groups based on the trip purpose. Thorhauge et al. (2016a) grouped car commuters based on their work time flexibility, their flexibility constraint across all daily trips and activities, and based on both criteria (flexibility and constraints). They found that the willingness to shift departure time is highest among people with flexible working hours and no constraints, while the willingness to pay is highest for people with fixed working times and constraints.

While segmentations based on socio-demographic variables allow for an easy identification of segment members who can then be targeted according to their specific needs, we assume that individuals with similar background variables still differ in their willingness to change their departure time choice as well as in other psychological factors that may determine departure time choice and potential behavioural change.

Psychographic segmentations provide better starting points for information and communication strategies as these can be adjusted to the attitudinal profiles of the segments (Haustein \& Hunecke, 2013). With regard to mode choice, psychographic segmentations have additionally shown higher predictive power than sociodemographic and spatial segmentations (Hunecke et al., 2010; Hunecke and Schweer, 2006). Therefore, this paper suggests a psychographic segmentation of commuters. 


\section{Procedure and participants}

\subsection{Measures}

Based on the Danish National Travel Survey (Transportvaneundersølgen, TU, Christiansen and Skovgaard, 2015) we designed an online questionnaire to collect the following data: (1) a full travel diary covering all trips and out-of-home activities within a 24 hour period during the latest working day, (2) detailed questions measuring the flexibility and constraints of each trip and activity in the travel diary, (3) a stated preference experiment enabling the estimation of departure time preferences, (4) psychological variables measuring attitudes, norms, and perceived barriers, and (5) background variables covering age, sex, income, location, household type and the flexibility of the start/end of the working hours.

The Stated Preference (SP) experiment contained hypothetical but realistic scenarios that were customised to match the respondents' travel characteristics (i.e. travel and departure time). Each choice task scenario consisted of three departure times (i.e. choice alternatives): the current departure time (i.e. the same as described in the daily trip part of the questionnaire), an earlier and a later departure time. The three alternatives included four attributes: departure time (DT), travel cost (TC), travel time (TT), and travel time variability (TTV). We defined travel costs by four level values, all other attributes by three. Using the software package Ngene (ChoiceMetrics, 2012), we constructed an efficient stated preference design. The final design included 27 choice tasks ( 3 blocks of 9 tasks). Each respondent had to select the preferred departure time alternative within each of nine choice tasks (see Thorhauge et al., 2014 for more details on the SP experiment setup).

Regarding the psychological factors, we included intention, attitude, subjective norm and perceived behavioural control as derived from the Theory of Planned Behaviour and added personal norm and perceived mobility necessities (see Section 2). More specifically, we included items measuring intention, attitude, subjective norm, and personal norm w.r.t. arriving on time (INT, ATT_on_time; SN; PN), attitude towards travel time (ATT_TT), attitude towards rescheduling (ATT_reschedule) and perceived mobility necessities (PMN). We measured all psychological constructs with three items on a five-point Likert scale (1 = strongly disagree; 5 = strongly agree), except for ATT_rechedule, which we measured by two items (see Table 2 for an item list).

\subsection{Sample description}

The target population of this study were commuters who were likely to experience congestion as they travel to the city centre of Copenhagen during the morning rush hours (arrival time between 6 and 10). This experience may motivate them to (re-)consider their departure time. While this is particular true for commuters by car and public transport, in case of Copenhagen this may also be relevant for bike commuters as cycling paths can be very crowded during rush hours. Copenhagen is the capital of Denmark and located 
in the eastern part of Zealand, the largest island of Denmark. The Greater Copenhagen Area has a population of 1.3 million inhabitants, with a population density of 2,532 inhabitants per $\mathrm{km}^{2}$ (Statistics Denmark, 2018). The labour market comprises about 0.9 million jobs and the unemployment rate is $4.7 \%$.

We collected data from two universities and three of the largest public organisations located in the centre of Copenhagen, where employees are likely to be affected by congestion to work. We invited all employees to answer the questionnaire regardless of their job type. We distributed more than 10,000 invitations via email, resulting in 923 fully completed questionnaires; 639 of these included a trip to work between 6-10 either by car (or other motorized individuals transport mode), public transport, bike or foot. The questionnaire only asked car users to complete the stated preference (SP) experiment $(N=286)$ as the main focus when designing the study was on car users. In this paper, we use the complete sample of 639 individuals to identify psychographic segments of commuters, while we use the SP-design applied to the sub-sample of car-users to validate the segments in terms of concurrent validity.

Table 1 summarises the main characteristics of the complete sample ( $N=639)$ compared to the Danish National Travel Survey of similar individuals (i.e. individuals who commute to the city centre of Copenhagen and arrive between 6-10 at work). Furthermore, the table shows the information about the subsegment of respondents who completed the stated preference experiment (i.e. the car users). First of all, our sample cannot claim representativeness as it differs from the Danish National Travel Survey, in particular with regard to education level, work flexibility, work hours per week, and income. This is not surprising as the majority of our data were collected at universities in Copenhagen. In terms of gender, age, household composition, and commuting distance our sample is representative for commuters to Copenhagen.

Comparing the SP sample with the complete cluster sample, both are very similar with regard to demographic characteristics, such as age and level of education. However, the cluster sample shows greater variation in commuting distance than the SP sample, which can be explained by the differences in mode choice. 
Table 1: Descriptive statistics of the sample and comparison with TU survey

\begin{tabular}{|c|c|c|c|c|}
\hline & & $\begin{array}{l}\begin{array}{l}\text { SP Sample } \\
\text { (car users) }\end{array} \\
(N=286)\end{array}$ & $\begin{array}{l}\text { Cluster } \\
\text { Sample } \\
(N=639)\end{array}$ & $\begin{array}{c}\text { Danish } \\
\text { National } \\
\text { Travel Survey } \\
(N=30123)\end{array}$ \\
\hline \multirow[t]{3}{*}{ Age } & $18-39$ & $25.8 \%$ & $29.1 \%$ & $29.4 \%$ \\
\hline & $40-59$ & $58.4 \%$ & $56.0 \%$ & $60.4 \%$ \\
\hline & $60+$ & $15.7 \%$ & $14.9 \%$ & $10.1 \%$ \\
\hline Gender & Male & $50.3 \%$ & $53.8 \%$ & $55.9 \%$ \\
\hline Education & Higher education & $93.4 \%$ & $93.6 \%$ & $58.5 \%$ \\
\hline Household type & Households with children & $59.4 \%$ & $56.7 \%$ & $57.2 \%$ \\
\hline \multirow[t]{3}{*}{ Work flexibility } & Fixed start/end work time & $33.6 \%$ & $25.0 \%$ & $36.4 \%$ \\
\hline & Flexible start/end work time & $65.0 \%$ & $72.2 \%$ & $22.6 \%$ \\
\hline & Unemployed/unknown & $1.4 \%$ & $2.8 \%$ & $40.9 \%$ \\
\hline \multirow{3}{*}{$\begin{array}{l}\text { Work hours } \\
\text { per week }\end{array}$} & Less than 37 hours & $8.4 \%$ & $10.6 \%$ & $16.6 \%$ \\
\hline & 37 hours & $29.4 \%$ & $30.8 \%$ & $49.1 \%$ \\
\hline & More than 37 hours & $62.2 \%$ & $58.5 \%$ & $34.2 \%$ \\
\hline \multirow{4}{*}{$\begin{array}{l}\text { Individual } \\
\text { income } \\
\text { [1000 DKK] }\end{array}$} & Low $<300)$ & $4.5 \%$ & $4.9 \%$ & $12.9 \%$ \\
\hline & Medium (300-600) & $49.7 \%$ & $54.8 \%$ & $53.4 \%$ \\
\hline & High $(>600)$ & $36.4 \%$ & $30.4 \%$ & $18.3 \%$ \\
\hline & Unknown & $8.7 \%$ & $10.0 \%$ & $6.9 \%$ \\
\hline \multirow{4}{*}{$\begin{array}{l}\text { Commuting } \\
\text { distance [km] }\end{array}$} & $1-10$ & $25.2 \%$ & $42.6 \%$ & $33.0 \%$ \\
\hline & $11-20$ & $30.4 \%$ & $20.3 \%$ & $27.6 \%$ \\
\hline & $21-50$ & $43.6 \%$ & $28.5 \%$ & $33.7 \%$ \\
\hline & More than 50 & $0.7 \%$ & $8.6 \%$ & $5.7 \%$ \\
\hline Commuting type & Escorting during trip to work & $13.6 \%$ & $14.7 \%$ & $9.4 \%$ \\
\hline \multirow[t]{4}{*}{ Primary mode } & Motorized individual vehicle & $100.0 \%$ & $60.1 \%$ & $67.8 \%$ \\
\hline & Public transport & $0.0 \%$ & $9.1 \%$ & $9.3 \%$ \\
\hline & Bike & $0.0 \%$ & $29.0 \%$ & $19.0 \%$ \\
\hline & Foot & $0.0 \%$ & $1.9 \%$ & $3.9 \%$ \\
\hline
\end{tabular}

Note. ${ }^{\text {a } 37 ~ h o u r s ~ i s ~ t h e ~ n o r m ~ f o r ~ a ~ s t a n d a r d ~ w o r k i n g ~ w e e k ~ i n ~ D e n m a r k . ~ T h e ~ n u m b e r ~ o f ~ w o r k i n g ~ h o u r s ~ i n c l u d e s ~}$ the total working hours per week regardless of whether the work is conducted from the work place or another location, for example home.

\section{Data analysis}

\subsection{Identification of psychographic commuter segments}

We identified the psychographic commuter segments in two steps: First, we conducted a principal component analysis (PCA) with varimax rotation to extract the underlying factors of the included psychological variables. Second, we used the psychographic factors as input variables in cluster analysis. 
The PCA resulted in a 5-factor solution, which explained 71\% of the variance. Table 2 presents the loadings of the single items on the five factors. The factors correspond to the expected underlying psychological constructs with one exception: attitude towards being on time and the related personal norm load highest on the same factor and will thus be regarded as one construct (Att_PN on time).

Table 2: Results of a principal component analysis on attitudinal items

\begin{tabular}{|c|c|c|c|c|c|c|}
\hline & & $\begin{array}{l}\text { Att_PN_ } \\
\text { on time }\end{array}$ & $\begin{array}{l}\text { SN_on } \\
\text { time }\end{array}$ & PMN & Att_TT & $\begin{array}{l}\text { Att_rech } \\
\text { edule }\end{array}$ \\
\hline $\begin{array}{l}\text { Att_on } \\
\text { time_1 }\end{array}$ & $\begin{array}{l}\text { Being late for work is very } \\
\text { unpleasant for me. }\end{array}$ & .853 & .114 & .103 & .031 & .015 \\
\hline $\begin{array}{l}\text { Att_on } \\
\text { time_2 }\end{array}$ & $\begin{array}{l}\text { It is very important for me to be at } \\
\text { work on time. }\end{array}$ & .827 & .199 & .081 & .021 & -.053 \\
\hline $\begin{array}{l}\text { Att_on } \\
\text { time_3 }\end{array}$ & $\begin{array}{l}\text { It is problematic for me to be late for } \\
\text { work. }\end{array}$ & .741 & .163 & .069 & .102 & -.097 \\
\hline PN_1 & $\begin{array}{l}\text { Being late for work is against my } \\
\text { principles. }\end{array}$ & .744 & .200 & .058 & -.017 & .011 \\
\hline PN_2 & I feel obliged to be at work on time. & .741 & .367 & .083 & -.054 & -.065 \\
\hline PN_3 & $\begin{array}{l}\text { I feel very bad about being late for } \\
\text { work. }\end{array}$ & .827 & .198 & .072 & -.009 & .018 \\
\hline SN_1 & $\begin{array}{l}\text { My boss thinks that I should be at } \\
\text { work on time. }\end{array}$ & .364 & .810 & .029 & -.005 & -.024 \\
\hline SN_2 & $\begin{array}{l}\text { My colleagues think that I should be } \\
\text { at work on time. }\end{array}$ & .310 & .846 & .047 & -.027 & -.064 \\
\hline SN_3 & $\begin{array}{l}\text { People, who are important to me, } \\
\text { think that I should be at work on } \\
\text { time. }\end{array}$ & .281 & .808 & .080 & .031 & -.007 \\
\hline PMN_1 & $\begin{array}{l}\text { My work requires a high level of } \\
\text { mobility. }\end{array}$ & .122 & -.014 & .842 & -.003 & .015 \\
\hline PMN_2 & $\begin{array}{l}\text { The organization of my everyday life } \\
\text { requires a high level of mobility. }\end{array}$ & .108 & .080 & .866 & .045 & -.006 \\
\hline PMN_3 & $\begin{array}{l}\text { I have to be mobile all the time to } \\
\text { meet my obligations. }\end{array}$ & .071 & .076 & .872 & -.004 & -.021 \\
\hline Att_TT_1 & $\begin{array}{l}\text { It is very important for me to have a } \\
\text { short TT to/from work. }\end{array}$ & .044 & .001 & -.006 & .775 & -.102 \\
\hline Att_TT_2 & $\begin{array}{l}\text { Having a long TT to/from work is } \\
\text { very stressful for me. }\end{array}$ & .012 & -.011 & .028 & .776 & .038 \\
\hline Att_TT_3 & $\begin{array}{l}\text { I don't care about long TT to my } \\
\text { work. }\end{array}$ & .002 & -.007 & -.011 & -.749 & -.096 \\
\hline At_re_1 & $\begin{array}{l}\text { I am willing to depart earlier or later } \\
\text { if it can reduce my TT. }\end{array}$ & .004 & -.066 & .009 & .032 & .879 \\
\hline Att_re_2 & $\begin{array}{l}\text { I am willing to change my work time } \\
\text { to avoid rush hours. }\end{array}$ & -.091 & -.003 & -.017 & .006 & .878 \\
\hline $\begin{array}{l}\text { Cronbach's } \\
\text { Alpha }\end{array}$ & & .90 & .86 & .84 & .65 & .72 \\
\hline
\end{tabular}


With Cronbach's between .65 and .90, the five factors show acceptable internal consistencies and the items of each factor were merged to five mean scales, serving as input variables in the cluster analysis. Three items measuring intention to arrive on time were also merged to a mean scale (Cronbach's alpha $=.80$ ), serving as criterion variable in the cluster process.

As the second step towards the psychographic segmentation, cluster analysis was conducted based on the kmeans algorithms. As this method does not offer a way to calculate the optimal number of clusters, we conducted analyses for two to five cluster solutions based on the five mean scales (after performing zstandardisation).

We compared the different solutions based on their predictive power and interpretability. For assessing predictive power, we used intention to arrive at work on time as a criterion variable, serving as a proxy of departure time choice. Table 3 presents the results of ANOVAs for the different cluster solutions. With relative high increases in $\mathrm{Eta}^{2}$, the three cluster solution and the five cluster solution appear superior, in particular as compared to the four cluster solution where the Eta ${ }^{2}$ value decreases, while it is expected to increase with increasing number of clusters.

Table 3: ANOVA results for two to five clusters

\begin{tabular}{lll}
\hline & \multicolumn{2}{l}{$\begin{array}{l}\text { ANOVAs (Intention to arrive on } \\
\text { time) }\end{array}$} \\
\hline Number of clusters & $F$-value & $\mathrm{Eta}^{2}$ \\
\hline 2 & $316.67^{* * *}$ & .332 \\
3 & $180.01^{* * *}$ & .361 \\
4 & $112.97^{* * *}$ & .348 \\
5 & $102.78^{* * *}$ & .393 \\
\hline
\end{tabular}

Note. ${ }^{* * *} p<.001$

We used the interpretability of the different cluster solutions as the main criterion for choosing the appropriate number of clusters. Considering all solutions, we chose the three cluster solution because it resulted in most distinct cluster profiles and showed the highest continuity between the different solutions.

We finally checked the results of different initialisations of k-means for the three cluster solution. In most cases exactly the same allocation of cases to clusters was achieved. In single cases, where cluster membership changed, this never changed the overall profiles of the three clusters. Section 5.1 describes the final three cluster solution: the psychographic commuter segments.

\subsection{Assessing concurrent validity based on a discrete choice model}

To assess the criterion validity of the clusters (i.e. if they discriminate in what they are supposed to discriminate, namely departure time choice) we used the data collected in the SP experiment to estimate a discrete choice model (DCM) with cluster specific preferences. We examined whether clusters differ in their 
departure time preferences by making decisions that are in line with their psychological profile ${ }^{1}$. This comparison based on two different measures (clusters based on agreement to attitudinal statements; DCM based on SP experiment data), collected at the same time, refers to the psychological concept of congruent validity (as opposed to predictive validity).

Following the literature review in Section 2.1, a Scheduling Model (SM) is used to model departure time choice. Let be $U$ the utility that each traveller $(n)$ associates to the departure time $(j)$, which depends on the travel cost (TC); the expected travel time (E(TT)) from origin to destination weighted by the probability of experiencing additional (unforeseen) travel time; the weighted expected scheduled delay early (E(SDE)) and late (E(SDL)), i.e. the difference between the individual preferred arrival time and the actual arrival time, and an extra penalty for being late (DL). By introducing psychographic clusters in the Scheduling Model, we allow rescheduling preferences to differ among different segments of the population. The final utility function takes the following form:

$$
\begin{aligned}
U_{j n t}=A S C_{j}+ & \sum_{c=1}^{C}\left[I_{n c}\right. \\
& \left.*\left[\beta_{C}^{T T} E\left(T T_{j n t}\right)+\beta_{C}^{T C} T C_{j n t}+\beta_{C}^{S D E} E\left(S D E_{j n t}\right)+\beta_{C}^{S D L} E\left(S D L_{j n t}\right)+\beta_{C}^{D L} D L_{j n t}\right]\right] \\
& +\mu_{j n}+\varepsilon_{j n t}
\end{aligned}
$$

where, $A S C_{j}$ are alternative specific constant for alternative $j$, while $I_{n c}$ is a cluster-indicator, which is 1 if individual $n$ belongs to cluster $c, 0$ otherwise. Furthermore, $\varepsilon_{j n t}$ is a typical extreme value type 1 random term, independent among alternatives $j$, respondents $n$ and among repeated observations from the same individual ( $t$ ), while $\mu_{j n}$ is a random term normally distributed that accounts for panel correlation among repeated observations from the same individual. Following Noland et al. (1998), Small et al. (2000), and Börjesson (2007) we define $\mathrm{E}(T T)$ as the sum of the travel time weighted by the probability $\left(p_{i}\right)$ that each travel time occurs:

$$
E\left(T T_{j n t}\right)=\sum_{i=1}^{I} p_{i} \cdot T T_{j n t i}
$$

${ }^{1}$ Cluster specific preferences could have been estimated using latent class (LC) models. However, in LC models, the class membership is estimated jointly with the discrete choice, so the method cannot be used as a concurrent validation of the psychographic clusters, which is part of the objectives of this paper. 
Analogously $E(S D E)$ and $E(S D L)$ are the expected scheduling delays for early and late arrival, respectively, and are defined as:

$$
\begin{gathered}
E\left(S D E_{j n t}\right)=\max \left(-D T_{j n t}+E\left(T T_{j n t}\right)-P A T ; 0\right) \\
E\left(S D L_{j n t}\right)=\max \left(0 ; D T_{j n t}+E\left(T T_{j n t}\right)-P A T\right)
\end{gathered}
$$

\section{Results}

This section first describes the psychographic commuter segments (Section 5.1) and then assesses their concurrent validity based on a discrete choice experiment (Section 5.2). Based on a toll ring scenario, Section 5.3 demonstrates to what extent the identified commuter segments change departure time choice in response to an economic intervention.

\subsection{Commuter segments}

As a result of cluster analysis (see Section 4.1), we identified three psychographic commuter segments. Figure 1 shows their distinct psychographic profiles, which differ in particular with regard to attitudes towards travel time and attitudes and social norms with regard to arriving on time, while differences in attitudes to reschedule are less pronounced. To complement the psychographic profiles, we examined whether the segments also differed in demographic variables. Table 4 shows the results of this comparison, including tests for significance.

Taking together the results of Figure 1 and Table 4, we characterise the segments as follows: The first and smallest commuter segment (25\%) consists of people who find it important to arrive on time, and also perceive social pressure to do so. However, their most striking characteristic is that they consider it as less important to have a short travel time, why we call them 'Unhurried timely commuters'. Members of this segment are more often male and more often above 60 years of age. They have longer commuting distances and more often use public transport; both is probably related to the acceptance of longer travel times.

Members of the second segment (37\%) find it least important to arrive on time and also feel no social pressure in that direction. In line with that, they are more willing to reschedule their departure time to avoid the rush hour. They perceive the lowest level of mobility necessities and we thus call them 'Self-determined commuters'. While they work more often on flextime and are younger, they have lower incomes and more frequent childcare obligations, which may restrict their possibilities to reschedule departure time choice.

Members of the third segment (38\%) find it both very important to have a short travel time and to arrive on time, and they also feel most pressure to do so. In addition, they perceive the highest mobility necessities, which is why we call them 'Busy commuters'. Like the Unhurried timely commuters they are less willing to reschedule their departure time. Busy commuters are more often female, overrepresented in the age category 
between 40 and 59 years, and more often commute by car. Based on their profile they seem to experience the most stressful daily life.

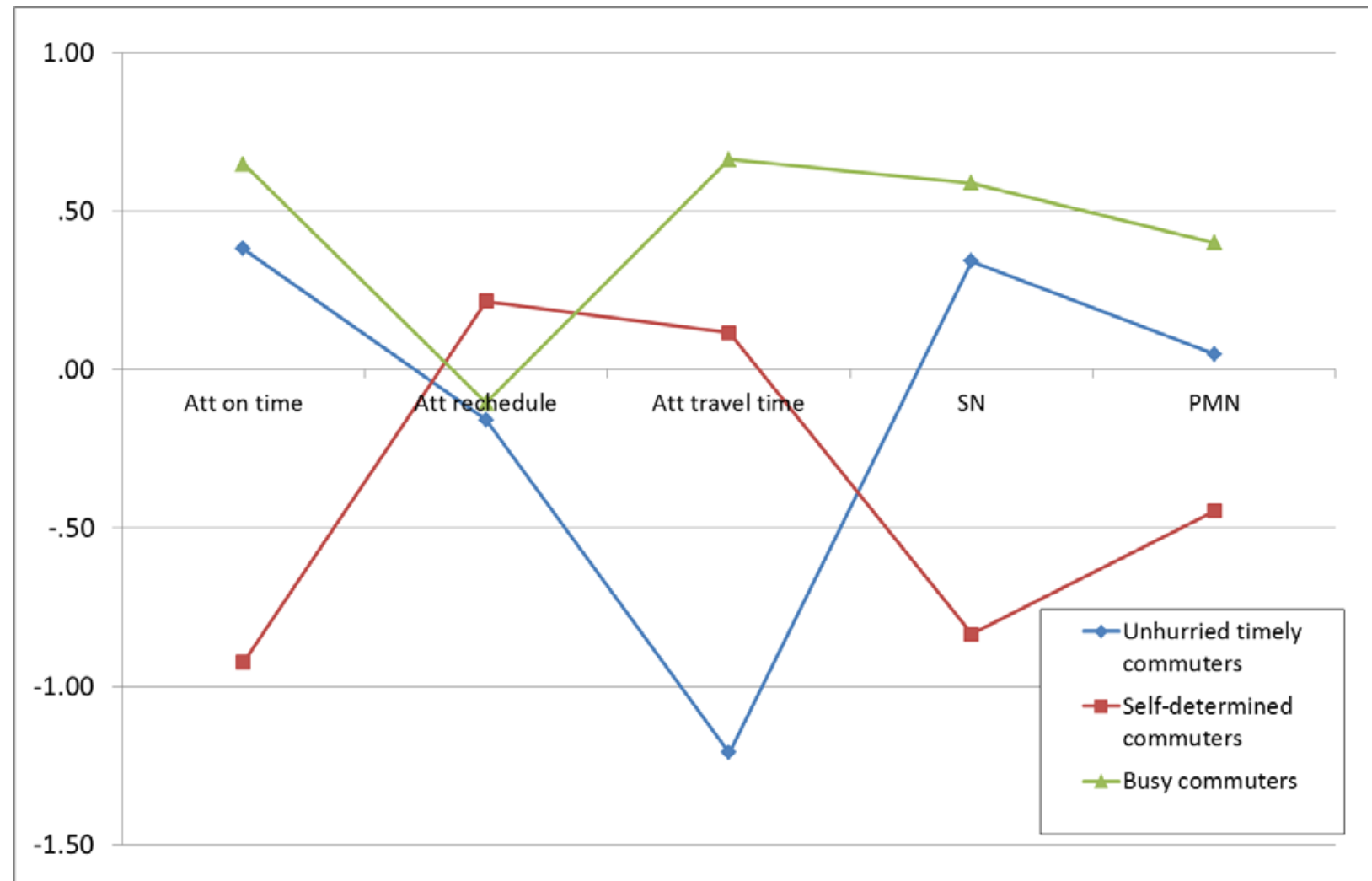

Figure 1: Psychographic profiles of commuter segments 
Table 4: Cluster description based on socio-demographic variables

\begin{tabular}{|c|c|c|c|c|c|}
\hline & & $\begin{array}{l}\text { Unhurried } \\
\text { timely } \\
\text { commuters } \\
(N=157) \\
\end{array}$ & $\begin{array}{c}\text { Self- } \\
\text { determined } \\
\text { commuters } \\
(N=237) \\
\end{array}$ & $\begin{array}{c}\text { Busy } \\
\text { commuters } \\
(N=245)\end{array}$ & $\chi^{2}$ test results \\
\hline \multirow[t]{3}{*}{ Age } & $18-39$ & $26.8 \%$ & $37.1 \%$ & $22.9 \%$ & $\chi^{2}(4, N=639)=$ \\
\hline & $40-59$ & $52.2 \%$ & $48.5 \%$ & $65.7 \%$ & $21.71, p<.001$ \\
\hline & $60+$ & $21.0 \%$ & $14.3 \%$ & $11.4 \%$ & \\
\hline Gender & Male & $63.7 \%$ & $54.4 \%$ & $46.9 \%$ & $\begin{array}{l}\chi^{2}(2, N=639)= \\
10.86, p<.01\end{array}$ \\
\hline Education & Higher education & $93.6 \%$ & $94.9 \%$ & $92.2 \%$ & $\begin{array}{l}\chi^{2}(2, N=639)= \\
1.45, p=.483\end{array}$ \\
\hline Household type & $\begin{array}{l}\text { Households with } \\
\text { children }\end{array}$ & $43.9 \%$ & $49.8 \%$ & $53.9 \%$ & $\begin{array}{l}\chi^{2}(2, N=639)= \\
3.78, p=.151\end{array}$ \\
\hline Work flexibility & $\begin{array}{l}\text { Flexible start/end } \\
\text { work time }\end{array}$ & $63.2 \%$ & $91.3 \%$ & $65.0 \%$ & $\begin{array}{l}\chi^{2}(2, N=621)= \\
55.18, p<.001\end{array}$ \\
\hline $\begin{array}{l}\text { Work hours } \\
\text { per week }\end{array}$ & $\begin{array}{l}<37 \text { hours } \\
37 \text { hours } \\
>37 \text { hours }\end{array}$ & $\begin{array}{l}8.4 \% \\
27.7 \% \\
63.9 \% \\
\end{array}$ & $\begin{array}{c}9.5 \% \\
35.8 \% \\
54.7 \% \\
\end{array}$ & $\begin{array}{l}9.5 \% \\
29.3 \% \\
61.2 \% \\
\end{array}$ & $\begin{array}{l}\chi^{2}(4, N=629)= \\
4.06, p=.40\end{array}$ \\
\hline $\begin{array}{l}\text { Individual } \\
\text { income } \\
\text { [1000 DKK] }\end{array}$ & $\begin{array}{l}\text { Low }<300) \\
\text { Medium }(300-600) \\
\text { High }(>600)\end{array}$ & $\begin{array}{c}3.6 \% \\
62.3 \% \\
34.1 \% \\
\end{array}$ & $\begin{array}{c}5.1 \% \\
78.5 \% \\
16.4 \% \\
\end{array}$ & $\begin{array}{c}6.7 \% \\
61.9 \% \\
31.4 \% \\
\end{array}$ & $\begin{array}{l}\chi^{2}(4, N=575)= \\
20.03, p<.001\end{array}$ \\
\hline $\begin{array}{l}\text { Commuting } \\
\text { distance }[\mathrm{km}]\end{array}$ & $\begin{array}{l}1-10 \\
11-20 \\
21-50 \\
\text { More than } 50\end{array}$ & $\begin{array}{l}31.8 \% \\
16.9 \% \\
35.7 \% \\
15.6 \% \\
\end{array}$ & $\begin{array}{c}50.9 \% \\
17.9 \% \\
22.6 \% \\
8.5 \% \\
\end{array}$ & $\begin{array}{c}43.0 \% \\
24.0 \% \\
29.8 \% \\
3.3 \% \\
\end{array}$ & $\begin{array}{l}\chi^{2}(6, N=630)= \\
33.91, p<.001\end{array}$ \\
\hline Commuting type & $\begin{array}{l}\text { Escorting during } \\
\text { trip to work }\end{array}$ & $10.8 \%$ & $18.1 \%$ & $13.9 \%$ & $\begin{array}{l}\chi^{2}(2, N=639)= \\
4.29, p=.120\end{array}$ \\
\hline Primary mode & $\begin{array}{l}\text { Motorized } \\
\text { individual vehicle } \\
\text { Public transport } \\
\text { Bike } \\
\text { Foot }\end{array}$ & $\begin{array}{c}62.4 \% \\
14.6 \% \\
21.7 \% \\
1.3 \% \\
\end{array}$ & $\begin{array}{c}54.9 \% \\
\\
9.7 \% \\
32.9 \% \\
2.5 \% \\
\end{array}$ & $\begin{array}{c}4.9 \% \\
29.8 \% \\
1.6 \%\end{array}$ & $\begin{array}{l}\chi^{2}(6, N=639)= \\
17.09, p=.009\end{array}$ \\
\hline
\end{tabular}

\subsection{Concurrent validity of clusters}

Table 5 reports the results of the departure time choice models with cluster specific preferences. The models were estimated as discrete choice models among the 286 car-users who answered the stated preference design, in which three alternatives were defined: Early departure, late departure and a departure time similar to the one reported by the survey participants. In order to account for correlation among responses from the same individuals we estimated Mixed Logit (ML) models. The models were based on a total of 2515 observations and estimated and simulated using PythonBiogeme v2.3 (Bierlaire and Fetiarison, 2009, see 
Section 4.2).

Based on the discrete choice models, we want to validate the following hypotheses that we derived from the psychographic profiles of the commuter segments:

H1: Because they place high importance to arriving on time and comparable low importance to having a short travel time, Unhurried timely commuters do not reschedule their departure time even if that implies longer travel time and higher travel costs.

H2: Because they place high importance to having a short travel time, while arriving on time is of minor importance, Self-determined commuters reschedule more than the other two segments.

H3: Because they place high importance to both arriving on time and having a short arrival time, Busy commuters lie in between the other two clusters with regard to rescheduling. As their psychographic profile as a whole is much closer to segment 1 than to segment 2, they react more similar to cluster 1 (i.e. they rather not compromise with being on time).

As Table 5 shows, the level-of-service parameters of the Scheduling model are all highly significant and negative (as expected), except for the discrete lateness penalty (DL) for Self-determined commuters. The insignificant result makes sense as Self-determined commuters find arrival time less important. For all three clusters the penalty for late arrival is greater than the penalty for early arrival, which is in line with the majority of the literature (Arellana et al., 2012; Asensio and Matas, 2008; Börjesson, 2008, 2007; De Jong et al., 2003; Hendrickson and Planke, 1984; Hess et al., 2007a, 2007b; Koster et al., 2011; Koster and Verhoef, 2012).

Before we continue discussing the differences in preferences among clusters, we first consider whether the estimated parameters are stable when controlling for work hour flexibility. When comparing model M1, which only includes level-of-service attributes, and model M2, which includes also work hour flexibility, we find that all the parameters are stable. This indicates that the parameters reflect actual preferences of the clusters, and are not just mimicking work hour flexibility. We also tested flexibility parameters specific for each cluster (M3), but found no significant difference among clusters (model M3 was not significantly superior to model M2). We also tested cluster alternative specific constants (results not presented), which were not significantly different among clusters either. Thus, we consider M2 as the final model, which is also supported by $\chi^{2}$-tests of the final log-likelihood.

The model results show that Self-determined commuters have the highest marginal disutility for travel time and cost, and the lowest for re-scheduling (considering both the discrete lateness penalty and the time dependent lateness penalty). Furthermore, the discrete lateness penalty is not significantly different from zero 
for Self-determined commuters. This confirms our hypothesis H2 that Self-determined commuters have the highest preference for a short travel time and are willing to reschedule to reduce travel time and cost.

The model also shows that opposed to Self-determined commuters, Unhurried timely commuters have the highest disutility of travel time, which confirms our hypothesis H1 that members of this segment care a lot about being on time; indeed so much that they completely sacrifice having a short travel time. The model confirms that Unhurried timely commuters have lower penalties for travel time and cost than Selfdetermined commuters. In the SP-design, the early and late departure time options were cheaper, to provide an incentive for people to change departure time. Unhurried timely commuters have the lower travel time and cost penalties, thus they are willing to travel during rush hours despite longer travel time and higher costs to arrive on time, confirming hypothesis H1.

Finally, model results also confirm that Busy commuters can be considered as a hybrid between Selfdetermined commuters and Unhurried timely commuters: their marginal utility for travel time and cost is not significantly different from that of the Unhurried timely commuters ( $t$-test; $p>.10$ ), while the marginal utility for late arrival is lower $(p=.06)$. The ratio between ESDL/ETT for Unhurried timely commuters is 0.695, while it is 0.460 for Busy commuters. Thus, the marginal rate of substitution (i.e. the relative penalty for late arrival with respect to the travel time penalty) is higher for Unhurried timely commuters than for Busy commuters. However, Busy commuters have a discrete lateness penalty that is three times larger than that of Unhurried timely commuters. This indicates that minor delays are more critical for Busy commuters because it is extremely important to be timely, while the magnitude of the delay is less important (the "damage" is done in the moment they are late). Overall, both clusters are in many ways similar with respect to parameter estimates, supporting our third hypothesis (H3). 
Table 5: Model estimates

\begin{tabular}{|c|c|c|c|c|c|c|}
\hline & \multicolumn{2}{|l|}{ M1 } & \multicolumn{2}{|l|}{ M2 } & \multicolumn{2}{|l|}{ M3 } \\
\hline & Value & $t$-test & Value & t-test & Value & $t$-test \\
\hline \multicolumn{7}{|l|}{ Parameter estimates } \\
\hline \multicolumn{7}{|c|}{ Cluster 1: Unhurried timely commuters (Obs $=635, N=72$ ) } \\
\hline Expected Travel Time & -0.161 & $-5.11 * * *$ & -0.164 & $-5.23 * * *$ & -0.169 & $-5.01 * * *$ \\
\hline Travel Cost & -0.147 & $-7.35 * * *$ & -0.150 & $-7.52 * * *$ & -0.151 & $-6.99 * * *$ \\
\hline Expected Scheduling Delay Early & -0.044 & $-3.49 * * *$ & -0.044 & $-3.52 * * *$ & -0.046 & $-3.32 * * *$ \\
\hline Expected Scheduling Delay Late & -0.116 & $-5.58 * * *$ & -0.114 & $-5.62 * * *$ & -0.110 & $-5.18 * * *$ \\
\hline Discrete Lateness Penalty & -0.250 & -0.89 & -0.266 & -0.95 & -0.234 & -0.83 \\
\hline Flexible Work Hours, early arrival & & & & & 0.578 & 0.94 \\
\hline Flexible Work Hours, late arrival & & & & & 1.210 & $1.97 *$ \\
\hline \multicolumn{7}{|c|}{ Cluster 2: Self-determined commuters (Obs=777, $N=89$ ) } \\
\hline Expected Travel Time & -0.316 & $-9.98 * * *$ & -0.298 & $-9.65 * * *$ & -0.313 & $-8.89 * * *$ \\
\hline Travel Cost & -0.219 & $-8.39 * * *$ & -0.204 & $-7.87 * * *$ & -0.222 & $-6.96 * * *$ \\
\hline Expected Scheduling Delay Early & -0.028 & $-2.56 *$ & -0.027 & $-2.47 *$ & -0.022 & -1.79 \\
\hline Expected Scheduling Delay Late & -0.088 & $-6.47 * * *$ & -0.093 & $-6.81 * * *$ & -0.093 & $-6.24 * * *$ \\
\hline Discrete Lateness Penalty & 0.441 & 1.55 & 0.396 & 1.40 & 0.336 & 1.23 \\
\hline Flexible Work Hours, early arrival & & & & & -0.083 & -0.12 \\
\hline Flexible Work Hours, late arrival & & & & & 1.200 & $1.73 *$ \\
\hline \multicolumn{7}{|c|}{ Cluster 3: Busy commuters (Obs=1103, $N=125)$} \\
\hline Expected Travel Time & -0.158 & $-5.15 * * *$ & -0.162 & $-5.20 * * *$ & -0.149 & $-4.56 * * *$ \\
\hline Travel Cost & -0.133 & $-6.54 * * *$ & -0.137 & $-6.72 * * *$ & -0.125 & $-5.78 * * *$ \\
\hline Expected Scheduling Delay Early & -0.037 & $-3.95 * * *$ & -0.036 & $-3.90 * * *$ & -0.039 & $-3.94 * * *$ \\
\hline Expected Scheduling Delay Late & -0.076 & $-6.87 * * *$ & -0.074 & $-6.75 * * *$ & -0.077 & $-6.63 * * *$ \\
\hline Discrete Lateness Penalty & -0.816 & $-3.55 * * *$ & -0.796 & $-3.42 * * *$ & -0.767 & $-3.28 * *$ \\
\hline Flexible Work Hours, early arrival & & & & & 1.150 & $2.37 *$ \\
\hline Flexible Work Hours, late arrival & & & & & 2.070 & $4.18 * * *$ \\
\hline \multicolumn{7}{|c|}{ Generic across the entire sample (Obs $=2515, N=286$ ) } \\
\hline ASC, early arrival & -1.480 & $-3.67 * * *$ & -1.940 & $-3.95 * * *$ & -1.820 & $-3.64 * * *$ \\
\hline ASC, late arrival & -0.629 & -1.68 & -1.660 & $-3.66 * * *$ & -1.590 & $-3.45 * * *$ \\
\hline Flexible Work Hours, early arrival & & & 0.726 & 1.88 & & \\
\hline Flexible Work Hours, late arrival & & & 1.630 & $4.29 * * *$ & & \\
\hline Std. Dev, early arrival & -2.190 & $-12.65 * * *$ & -2.180 & $-12.53 * * *$ & -2.180 & $-12.62 * * *$ \\
\hline Std. Dev, late arrival & -2.670 & $-12.87 * * *$ & -2.540 & $-12.31 * * *$ & -2.510 & $-12.38 * * *$ \\
\hline Corr. early-late arrival & -1.480 & $-5.70 * * *$ & -1.400 & $-5.15 * * *$ & -1.350 & $-5.33 * * *$ \\
\hline \multicolumn{7}{|l|}{ Summary of model } \\
\hline Final log-likelihood: & \multicolumn{2}{|c|}{-1758.927} & \multicolumn{2}{|c|}{-1749.884} & \multicolumn{2}{|c|}{-1748.372} \\
\hline Number of draws: & \multicolumn{2}{|c|}{1000} & \multicolumn{2}{|c|}{1000} & \multicolumn{2}{|c|}{1000} \\
\hline Rho bar for the Null model: & \multicolumn{2}{|l|}{0.356} & \multicolumn{2}{|l|}{0.359} & \multicolumn{2}{|l|}{0.358} \\
\hline Rho for the Null model: & \multicolumn{2}{|l|}{0.363} & \multicolumn{2}{|l|}{0.367} & \multicolumn{2}{|l|}{0.367} \\
\hline Sample size: & \multicolumn{2}{|l|}{2515} & \multicolumn{2}{|l|}{2515} & \multicolumn{2}{|l|}{2515} \\
\hline
\end{tabular}

Note: ${ }^{*} p<.05 ;{ }^{* *} p<.01 ;{ }^{* * *} p<.001$ 


\subsection{Toll ring scenario}

As a final step we showcase how each of the clusters would react to an economic intervention. We assumed the introduction of a toll ring around Copenhagen, and computed the change in departure times for each cluster. We expected that segments, who find it important to be at work at a specific time, show less willingness to change their departure time. Similarly to Thorhauge et al. (2016a), we assumed a charge of 20 DKK (approximately 2.50 €) in the central peak period between 7:30-8:30, a charge of 10 DKK (approximately 1.25 $€$ ) between 7:00-7:30 and 8:30-9:00 and no charge during the shoulders of the rush hours (i.e. before 7:00 and after 9:00). A price range of 10-20 DKK is in line with the toll ring systems implemented in other Scandinavian cities, such as Stockholm, Gothenburg, and Oslo (Fjellinjen, 2015; Transportstyrelsen, 2015a, 2015b).

For the scenarios we defined 10 time periods consisting of 15 minutes' intervals between 7:00-9:00, and 1hour periods between 6:00-7:00 and 9:00-10:00. Level-of-Service (LoS) for each departure time slot was obtained from the Danish National Travel Survey (TU). The model estimated with the SP data was then calibrated to adjust constants and scaled to the real travel times observed in the Danish National Travel survey. Figure 2 shows the substitution patterns among individuals between the three segments. The substitution patterns are the difference in market shares before and after introducing a toll ring. The figure confirms our expectations based on the cluster profiles: Self-determined commuters re-schedule to the largest extend. This is in line with their low penalties for rescheduling, and overall fits with previous parameters and substitution patterns (Thorhauge et al., 2016a). Furthermore, Unhurried timely commuters, who value being on time, almost entirely avoid the late(r) departure time slots. The percentage of Busy commuters who reschedule their departure time so that it is before 7:00 a.m. or after 9:00 a.m. is slightly higher than the percentage of Unhurried timely commuters, but smaller than the percentage of Self-determined commuters. This is in line with our expectations. 


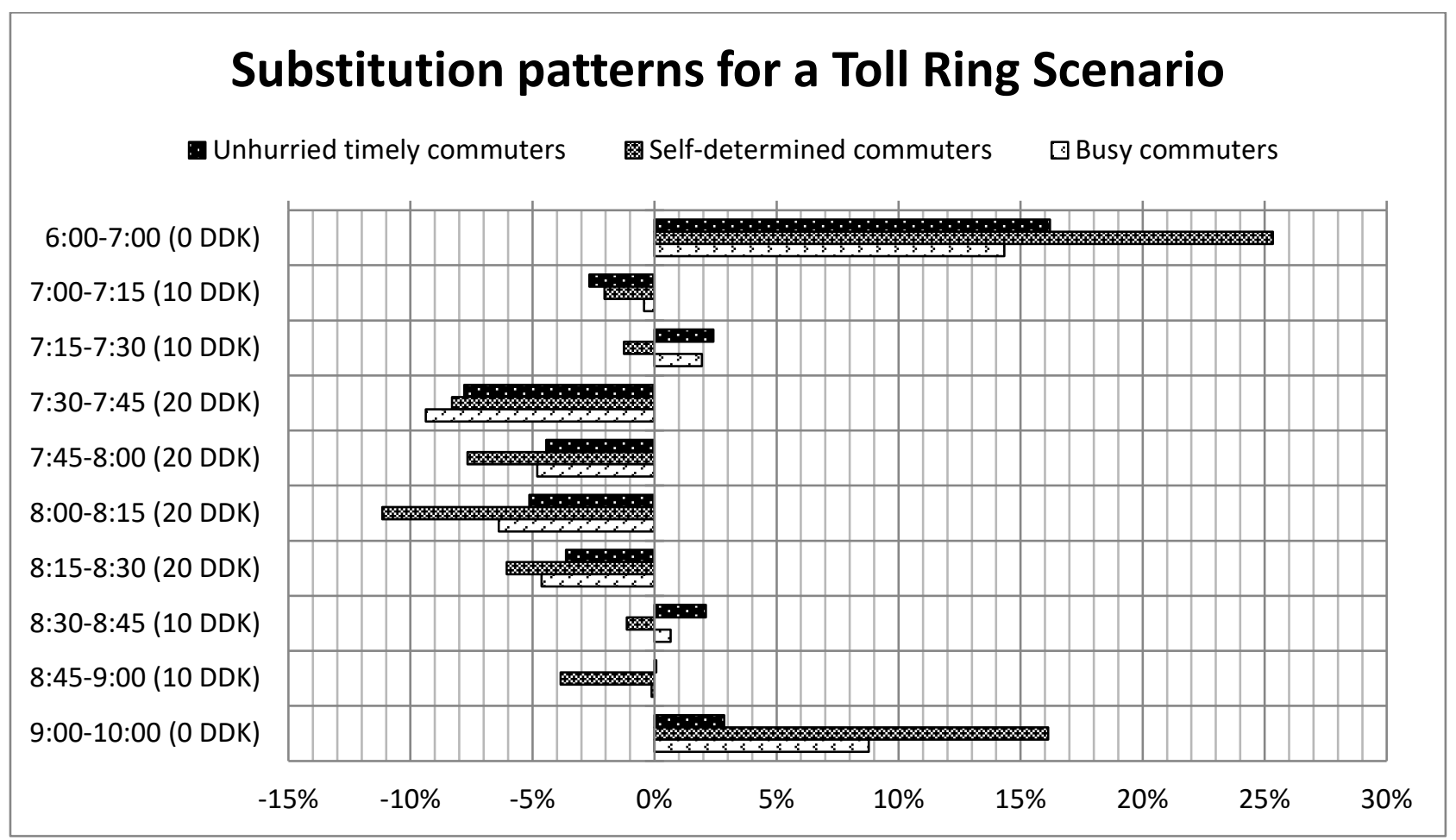

Figure 2: Substitution patterns due to the introduction of a toll ring for the three clusters.

\section{Discussion}

In this paper, we identified three commuter segments based on psychographic factors related to departure time choice: Unhurried timely commuters, who are least willing to change their departure time choice, mostly as it is not important for them to have a short travel time but very important to arrive on time; Selfdetermined commuters, who feel most free in their choices and are consequently most willing to reschedule to reduce travel time and costs (also when controlling for flexible work time schedules); and finally Busy commuters, who find it important to arrive on time and to have a short travel time and lie in-between the other clusters with regard to their willingness to reschedule.

The psychographic profiles are reflected in the preferences shown in a departure time choice model based on a stated preference experiment, which indicates high concurrent validity of the segmentation.

An striking characteristic of Unhurried timely commuters are their longer commuting distances, which reflect well that having a short travel time is not that important to them. Whether cluster members accept workplaces in longer distances as they do not mind travelling longer or whether they got used to travelling longer and adjusted their attitudes accordingly remains unclear. Longer commuting distances can also reflect residential self-selection, according to which there is a relation between "travel-liking attitudes" and residential location (De Vos and Witlox, 2016). Explanations may also be related to mode choice as travel 
time savings are valued differently for different transport modes. That public transport users are overrepresented among Unhurried timely commuters may indicate that people who find travel time savings less important are more likely to choose public transport; it may also indicate that people who use public transport can make better use of their travel time and thus find it less important to save it. Also here the cause and effect relation cannot be clarified and needs further investigation. An explanation for the lower importance of saving travel time may be related to the higher percentage of older people and men in this segment - people who are generally less involved in family obligations. This interpretation is supported by a recent Dutch study, showing that female gender and child care obligations have a positive effect on morning rush-hour commuting (Oakail et al., 2016).

Changes in departure time for Unhurried timely commuters can neither be motivated with shorter travel time nor with lower costs as the results of the toll ring scenario indicate. As the comparably high share of PT users among Unhurried timely commuters suggests, members of this group may be more open for the use of PT and thus current Unhurried timely car commuters might be the right target group to achieve a modal shift from the car to PT. Punctuality and reliability of the PT service appear as the most relevant features to promote a model shift for Unhurried timely commuters, while travel time savings and price are of minor importance.

A relevant difference between Unhurried timely commuters and Busy commuters is that for Busy commuters arriving on time is very important (and probably part of their self-identify) but once they are delayed, the amount of delay is less important for them. Compared to Unhurried timely commuters, Busy commuters are not much more willing but a bit more likely to reschedule. Apart from road pricing, the avoidance of commuting trips, for example by teleworking on selected workdays, might be the most effective way to reduce congestions caused by this group. This would probably also be perceived as a relief from a comparably stressful everyday life of this busy commuter segment.

For Self-determined commuters an economic intervention is a very efficient way to influence their behaviour, as demonstrated in the toll ring scenario, where approximately $40 \%$ are expected to change their departure time in response to that intervention, as compared to approximately $25 \%$ for the other two groups. The percentage of Self-determined commuters who reschedule is of the same magnitude as that of individuals with flexible working schedules in Thorhauge et al. (2016a) and both groups also match in terms of willingness to pay to avoid late arrival. This is not surprising as both groups highly overlap. More specifically, circa $90 \%$ of Self-determined commuters have flexible work schedules. However, the result that there are also larger shares of people with flextime in the other segments who are less willing to reschedule, indicates that flextime is a necessary condition for rescheduling but not a sufficient one. Nevertheless, in terms of identifying people who are likely to reschedule this single variable is similar successful as the psychographic clustering in this paper. However, we assume that our segments will show more similar 
behavioural patterns when their work conditions (or other external parameters) change, which needs to be confirmed by future research. The result that the working schedule was controlled for in the discrete choice model supports this assumption.

While the proposed toll ring is overall successful in generating departure time shifts (though not to the same extent in all segments), a clear disadvantage of this hard measure is that it requires substantial political and societal support to get implemented, which is often not given (Morris and Hirsch, 2016). Road user charging can also be criticised for equity reasons as it can increase social exclusion of disadvantaged groups (Bonsall and Kelly, 2005). Soft measures represent an alternative or supplementation of hard measures. As outlined earlier in this paper, market segmentation generally provides relevant starting points for the development of targeted soft measures. However, the specification of concrete soft measures for our three commuter segments requires more elaborated profiles.

We see three ways of improving the suggested segmentation: First, the inclusion of the value orientation "openness to change" as an additional cluster variable would clarify to what extent the unwillingness to change departure time reflects a persons’ more general aversion to changing habits. Second, a better operationalisation of personal norm to arrive on time (which loaded on the same factor as attitude) would give more insight whether the wish to arrive on time is based on an intrinsic or extrinsic motivation. Yet, also other studies "suggest a lack of discriminant validity between personal norm and attitude" (Lo et al., 2010, p. 2). Third, the inclusion of functional and symbolic motivations for the use of the different transport modes would offer a better basis for interventions. The knowledge of what people like or dislike in relation to the mode they use for commuting would probably explain differences in the attitude towards travel time and could be used for interventions to change departure time but also interventions for modal shifts, which is what we suggest for Unhurried timely commuters.

As we have stated in the sample description, our sample cannot claim representativeness. While distributions of age, gender and household type resemble city commuters in Copenhagen, the selection of included workplaces led to an overrepresentation of people with higher education. A more representative sample might lead to a different size of clusters or even slightly different cluster profiles, which is subject to further research. Another limitation of the study is that the validation of the segments was only based on car commuters. Although the validation and simulation for car users confirms the overall cluster profiles, further research is needed to show to what extent the conclusions can be transferred to commuters of other modes. We expect that the different valuation of travel time in relation to different transport modes, and in particular differences in that respect between the segments, gives valuable insights for the derivation of targeted interventions. 
This study focused on the departure time of morning commuters, which is typically the time of day with the highest congestion problems (see for the Danish context: Center for Transport Analytics, 2014). While some studies (Arellana et al. 2012, 2013; de Jong et al. 2003) also explicitly model the return trip from work, our data does not allow for that. However, we consider this as an interesting area for future research, in particular with regard to the question whether preferences are different and would lead to changes in the profiles of the identified segments.

\section{Conclusions}

This study presents a psychographic commuter segmentation based on an extended version of the Theory of Planned Behaviour (Ajzen, 1991). In transportation research and practise, similar approaches have so far mainly been developed and applied in the context of travel mode choice. A main motivation for applying market segmentations lies in the possibility to derive targeted measures to change behaviour based on the resulting psychographic profiles. We demonstrated that an economic intervention is not sufficient to achieve major behavioural changes in all identified commuter segments. For one segment, aiming for a modal shift appears more relevant, and for one segment teleworking could be an adequate solution. However, our commuter profiles do not provide sufficient knowledge to derive more specific measures for each segment. We think a main reason for this is that our segmentation is only based on psychographic factors related to departure time choice but left out more general value orientations and evaluations of the transport modes. Both additions would provide more background knowledge to explain the differences between the segments. We suggest considering travel mode choice and departure time choice more integrated in future studies, taking into account the most relevant determinants of both choices when creating new segmentation approaches.

\section{References}

Ajzen, I., 1991. The theory of planned behavior. Organ. Behav. Hum. Decis. Process. 50, 179-211. doi:10.1016/0749-5978(91)90020-T

Anable, J., 2005. “Complacent Car Addicts” or “Aspiring Environmentalists”? Identifying travel behaviour segments using attitude theory. Transp. Policy. doi:10.1016/j.tranpol.2004.11.004

Arellana, J., Daly, A., Hess, S., Ortúzar, J. de D., Rizzi, L.I., 2012. Development of Surveys for Study of Departure Time Choice Two-Stage Approach to Efficient Design. Transp. Res. Rec. 9-18. doi:10.3141/2303-02

Asensio, J., Matas, A., 2008. Commuters valuation of travel time variability. Transp. Res. Part E Logist. Transp. Rev. 44, 1074-1085. 
Bamberg, S., Hunecke, M., Blöbaum, A., 2007. Moral norm, social context and the use of public transport Results of two field studies. J Environ. Psychol. 27, 190-203.

Beirão, G., Sarsfield Cabral, J.A., 2007. Understanding attitudes towards public transport and private car: A qualitative study. Transp. Policy 14, 478-489. doi:10.1016/j.tranpol.2007.04.009

Bianchi, R., Jara-Diaz, S.R., Ortúzar, J. de D., 1998. Modelling new pricing strategies for the Santiago Metro. Transp. Policy 5, 223-232.

Bierlaire, M., Fetiarison, M., 2009. Estimation of discrete choice models: extending BIOGEME, in: 9th Swiss Transport Research Conference. Monte Veritá. Switzerland.

Böhler, S., Grischkat, S., Haustein, S., Hunecke, M., 2006. Encouraging environmentally sustainable holiday travel. Transp. Res. Part A Policy Pract. 40, 652-670. doi:10.1016/j.tra.2005.12.006

Bonsall, P., Kelly, C., 2005. Road user charging and social exclusion: The impact of congestion charges on at-risk groups. Transp. Policy 12, 406-418.

Börjesson, M., 2009. Modelling the preference for scheduled and unexpected delays. J. Choice Model. 2, 2950. doi:10.1016/S1755-5345(13)70003-4

Börjesson, M., 2008. Joint RP-SP data in a mixed logit analysis of trip timing decisions. Transp. Res. Part E Logist. Transp. Rev. 44, 1025-1038. doi:10.1016/j.tre.2007.11.001

Börjesson, M., 2007. Departure time modelling applicability and travel time uncertainty, in: Proceedings of the European Transport Conference. Association for European Transport (AET), Leiden, The Netherlands.

Börjesson, M., Eliasson, J., Franklin, J.P., 2012. Valuations of travel time variability in scheduling versus mean-variance models. Transp. Res. Part B Methodol. 46, 855-873. doi:10.1016/j.trb.2012.02.004

ChoiceMetrics, 2012. Ngene software.

Christiansen, H., Skovgaard, B.Z., 2015. Documentation of the Danish National Travel Survey. DTU Transport, Data- and Modelcenter.

De Jong, G., Daly, A., Pieters, M., Vellay, C., Bradley, M., Hofman, F., 2003. A model for time of day and mode choice using error components logit. Transp. Res. Part E Logist. Transp. Rev. 39, 245-268.

De Vlieger, I., De Keukeleere, D., Kretzschmar, J. G., 2000. Environmental effects of driving behaviour and congestion related to passenger cars. Atmosph. Environ. 34(27), 4649-4655. 
De Vos, J., Witlox, F., 2016. Do people live in urban neighbourhoods because they do not like to travel? Analysing an alternative residential self-selection hypothesis. Travel Behav. Soc. 4, 29-39.

Fjellinjen, 2015. Oslo bomring: betaling og priser [WWW Document].

Fujii, S., Kitamura, R., 2004. Drivers’ mental representation of travel time and departure time choice in uncertain traffic network conditions. Networks Spat. Econ. 4, 243-256.

Haustein, S., Hunecke, M., 2013. Identifying target groups for environmentally sustainable transport: Assessment of different segmentation approaches. Curr. Opin. Environ. Sustain. 5, 197-204. doi:10.1016/j.cosust.2013.04.009

Haustein, S., Hunecke, M., 2007. Reduced use of environmentally friendly modes of transportation caused by perceived mobility necessities: An extension of the theory of planned behavior. J. Appl. Soc. Psychol. 37, 1856-1883. doi:10.1111/j.1559-1816.2007.00241.x

Hunecke M, Haustein S, Böhler S, Grischkat S., 2010. An attitude based target group approach to reduce the ecological impact of daily mobility behavior. Environ Behav 2010, 42:3-43.

Hunecke M, Schweer I., 2006. Einflussfaktoren der Alltagsmobilität - Das Zusammenwirken von Raum, Verkehrsinfrastruktur Lebensstil und Mobilitätseinstellungen. In K.J. Beckmann, M. Hesse, C. HolzRau, M. Hunecke. StadtLeben -Wohnen, Mobilität und Lebensstil (p. 148-166). VS Verlag für Sozialwissenschaften.

Hendrickson, C., Planke, E., 1984. The flexibility of departure times for work trips. Transp. Res. Part A Policy Pract. 18, 25-36.

Hess, S., Daly, A., Rohr, C., Hyman, G., 2007a. On the development of time period and mode choice models for use in large scale modelling forecasting systems. Transp. Res. Part A Policy Pract. 41, 802-826.

Hess, S., Polak, J.W., Daly, A., Hyman, G., 2007b. Flexible substitution patterns in models of mode and time of day choice: new evidence from the UK and the Netherlands. Transportation (Amst). 34, 213-238.

Hildebrand, E.D., 2003. Dimensions in elderly travel behaviour: A simplified activity-based model using lifestyle clusters. Transportation (Amst). 30, 285-306.

Hunecke, M., Haustein, S., Böhler, S., Grischkat, S., 2010. Attitude-based target groups to reduce the ecological impact of daily mobility behavior. Environ. Behav. 42, 3-43. doi:10.1177/0013916508319587

Hunecke, M., Schweer, I., 2006. Einflussfaktoren der Alltagsmobilität - Das Zusammenwirken von Raum, 
Verkehrsinfrastruktur, Lebensstil und Mobilitätseinstellungen, in: Beckmann K. J., Hesse M., Holz-Rau C, H. M. (Ed.), StadtLeben - Wohnen, Mobilität Und Lebensstil. VS Verlag für Sozialwissenschaften, pp. 148-166.

Koster, P., Kroes, E., Verhoef, E., 2011. Travel time variability and airport accessibility. Transp. Res. Part B Methodol. 45, 1545-1559.

Koster, P., Verhoef, E.T., 2012. A Rank-dependent Scheduling Model. J. Transp. Econ. Policy 46, 123-138.

Kristoffersson, I., 2013. Impacts of time-varying cordon pricing: Validation and application of mesoscopic model for Stockholm. Transp. Policy 28, 51-60. doi:10.1016/j.tranpol.2011.06.006

Kroes, E., Daly, A., Gunn, H., Van, D.H., 1996. Opening of the Amsterdam ring road: A case study on shortterm effects of removing a bottleneck. Transportation 23, 71-82.

Levy, J.I., Von Stackelberg, K., Buonocore, J.J., 2010. Evaluation of the public health impacts of traffic congestion: A health risk assessment. Environ. Heal. a Glob. Access Sci. Source 9(65), 1-12. doi:10.1186/1476-069X-9-65

Lo, S. H., Van Breukelen, G. J., Peters, G. J. Y., Kok, G., 2016. Commuting travel mode choice among office workers: Comparing an Extended Theory of Planned Behavior model between regions and organizational sectors. Travel Behav. Soc. 4, 1-10.

McKenzie-Mohr, D., 2000. New Ways to Promote Proenvironmental Behavior: Promoting Sustainable Behavior: An Introduction to Community-Based Social Marketing. J. Soc. Issues 56, 543-554. doi:10.1111/0022-4537.00183

Center for Transport Analytics, 2014. Faktaark om pendling i Danmark (Fact sheet on commuting 2014). Retrieved from: http://www.modelcenter.transport.dtu.dk/transportvaneundersoegelsen/tuudgivelser/faktaark-om-pendling-i-danmark-2014

Morris, E. A., Hirsch, J. A., 2016. Does rush hour see a rush of emotions? Driver mood in conditions likely to exhibit congestion. Travel Behav. Soc. 5, 5-13.

Noland, R., Small, K., 1995. Travel-time uncertainty, departure time choice, and the cost of morning commutes. Transp. Res. Rec. No. 1493, Travel Demand Forecast. Travel Behav. Anal. Time-Sensitive Transp. Traffic Assign. Methods 150-158.

Noland, R.B., Small, K.A., Koskenoja, P.M., Chu, X., 1998. Simulating travel reliability. Reg. Sci. Urban Econ. 28, 535-564. doi:10.1016/S0166-0462(98)00009-X 
Oakil, A. T. M., Nijland, L., Dijst, M., 2016. Rush hour commuting in the Netherlands: Gender-specific household activities and personal attitudes towards responsibility sharing. Travel Behav. Soc. 4, 79-87.

Polak, J.W., Jones, P.M., 1994. A tour-based model of journey scheduling under road pricing. 73rd Annual Meeting of the Transportation Research Board, Washington, DC.

Prillwitz, J., Barr, S., 2011. Moving towards sustainability? Mobility styles, attitudes and individual travel behaviour. J. Transp. Geogr. 19, 1590-1600. doi:10.1016/j.jtrangeo.2011.06.011

Pronello, C., Camusso, C., 2011. Travellers’ profiles definition using statistical multivariate analysis of attitudinal variables. J. Transp. Geogr. 19, 1294-1308. doi:10.1016/j.jtrangeo.2011.06.009

Ryley, T., 2006. Use of non-motorised modes and life stage in Edinburgh. J. Transp. Geogr. 14, 367-375. doi:10.1016/j.jtrangeo.2005.10.001

Schubert, S., Kamphausen, C., 2006. Multidimensionale Zielgruppen - Kundensegmentierung als Marketing-Instrument für einen Verkehrsverbund. Der Nahverkehr 24, 56-58.

Schwartz, S.H., 1977. Normative Influences on Altruism. Adv. Exp. Soc. Psychol. 10, 221-279. doi:10.1016/S0065-2601(08)60358-5

Siren, A., Haustein, S., 2013. Baby boomers' mobility patterns and preferences: What are the implications for future transport? Transp. Policy 29. doi:10.1016/j.tranpol.2013.05.001

Small, K.A., 1982. The scheduling of consumer activities: Work trips. Am. Econ. Rev. 72, 467-479. doi:10.1126/science.151.3712.867-a

Small, K.A., 1987. A discrete choice model for ordered alternatives. Econometrica 55, 409-424. doi:10.2307/1913243

Small, K.A., Noland, R.B., Chu, X., Lewis, D., 2000. NCHRP Report 431 - Valuation of travel-time savings and predictability in congested conditions for highway user-cost estimation. Transportation Research Board, National Research Counsil, National Cooporative Highway Research Program, Washington, United States of America.

Small, K.A., Noland, R.B., Koskenoja, P.M., 1995. Socio-economic attributes and impacts of travel reliability: a stated preference approach. California Partners for Advanced Transit and Highways (PATH), Institute of Transportation Studies (UCB), UC Berkeley.

Thorhauge, M., Cherchi, E., Rich, J., 2016a. How flexible is flexible? Accounting for the effect of rescheduling possibilities in choice of departure time for work trips. Transp. Res. Part A Policy Pract. 
86, 177-193. doi:10.1016/j.tra.2016.02.006

Thorhauge, M., Cherchi, E., Rich, J., 2014. Building efficient stated choice design for departure time choices using the scheduling model: Theoretical considerations and practical implementations, in: Presented at Aalborg Trafikdage 2014. Aalborg University, Aalborg, Denmark, pp. 1-15.

Thorhauge, M., Cherchi, E., Walker, J.L., Rich, J., 2016b. The role of intention as mediator between latent effects and current behavior: application of a hybrid choice model to study departure time choices. 95th Annual Meeting of the Transportation Research Board, Washington, DC.

Thorhauge, M., Haustein, S., Cherchi, E., 2016. Accounting for the Theory of Planned Behaviour in departure time choice. Transp. Res. Part F Traffic Psychol. Behav. 38, 94-105. doi:10.1016/j.trf.2016.01.009

Transportstyrelsen, 2015a. Trangselskatt i Stockholm: Tider och belopp i Stockholm [WWW Document]. Transportstyrelsen, 2015b. Trangselskatt i Göteborg: Tider och belopp i Goteborg [WWW Document].

Vlek, C. (2002). Motorised transport as a commons dilemma: ,Hard' and ,soft'strategies for a sustainable balance, in: OECD (Ed.), Communicating Environmentally Sustainable Transport, OECD, Paris, pp. 23-35. 